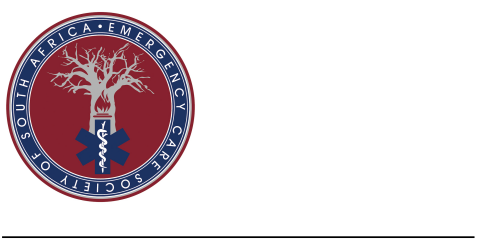

ARTICLE INFORMATION

Received: 30 July 2020

Revision received: 9 September 2020

Accepted: 15 September 2020

Keywords:

Emergency Medical Services

asthma

peak expiratory flow rate

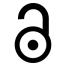

This open access article is distributed under Creative Commons licence CCBY-NC 4.0

ISSN:2709-3786

\section{Pre-hospital emergency care providers' knowledge and use of peak flow meters in the management of acute asthma in Johannesburg, South Africa}

\author{
Craig Vincent-Lambert*, Chrida Nkuna \\ Department of Emergency Medical Care, Faculty of Health Sciences, \\ University of Johannesburg
}

"Corresponding author: clambert@uj.ac.za, P O Box 524, Auckland Park, 2006

\begin{abstract}
Background: Peak flow meters (PFMs) measure the speed of airflow from the lungs during a forced exhalation. Current clinical practice guidelines advocate the use of PFMs in the management of acute asthma. No literature could be found describing local pre-hospital emergency care providers' use of PFMs. We aimed to investigate and describe a sample of prehospital emergency care providers' knowledge and use of PFMs in the management of acute asthma in Johannesburg, South Africa.

Methods: Fifty respondents (22 basic, 16 intermediate and 12 advanced life support providers) completed a pre-piloted questionnaire consisting of closed questions with pre-set response options focusing on exploring respondents' knowledge, understanding and use of PFMs.

Results: Responses highlighted a general lack of knowledge and understanding of PFMs. None of the basic life support providers, and only $19 \%$ of intermediate life support providers, indicated they had received training on the device. PFMs do not appear to be readily available in ambulances, with only $8 \%$ of the respondents indicating they had ever used a PFM on a real patient.

Conclusion: A lack of training on the device and its apparent unavailability are concerning since the peak expiratory flow rate (PEFR) measurement for asthma cases is considered best practice, and literature shows that emergency medical service (EMS) providers are commonly dispatched to asthmatic cases. Additional training and further research on the value and use of PFMs in local pre-hospital emergency care contexts is therefore recommended.
\end{abstract}

Vincent-Lambert C, Nkuna C. Pre-hospital emergency care providers' knowledge and use of peak flow meters in the management of acute asthma in Johannesburg, South Africa. South African Journal of Pre-hospital Emergency Care. 2020; 1(2):2-5. doi:10.24213/1-2-4223

\section{BACKGROUND}

Asthma is a common chronic disorder of the lower airway, characterised by recurring (usually reversible) symptoms related to airflow obstruction, bronchial hyper-responsiveness and underlying inflammation. ${ }^{1}$ The causes of this inflammation may be acute, sub-acute, or chronic. ${ }^{2}$ In acute phases, airway oedema and mucous secretion worsen airway obstruction and bronchial reactivity.

Aside from a comprehensive history and clinical assessment, several devices and tests can be used to support a diagnosis of asthma in both pre and 
in-hospital settings. These include pulse oximeters, allowing for non-invasive measurement and monitoring of oxygen saturation, as well as arterial and venous blood gas analysers.

Spirometers and peak flow meters (PFMs) are included in the range of devices available, both of which focus on physiological bronchodilatory responses. ${ }^{2,3}$ These portable handheld devices record a patient's ability to expel air and deliver a reading in litres per minute. ${ }^{4}$ Chest $\mathrm{x}$-rays may also be of value in diagnosing asthma, as they may show evidence of hyperinflation. However, such radiological findings are often only noted during episodes of acute exacerbation; between 'attacks', the lungs may appear normal. ${ }^{4}$ In prehospital settings, it is not currently a feasible option for local emergency care providers to take chest $\mathrm{x}$-rays. Therefore, in prehospital settings, measuring peak expiratory flow rates (PEFRs) using PFMs remains a more pragmatic assessment option to gauge the presence or severity of airflow restrictions, predominantly in the larger airways proximal to the terminal bronchioles and alveoli.

Accurately categorising the severity of airflow restriction during an acute exacerbation of asthma plays a role in clinical decision-making in terms of treatment interventions and the need for an escalation or de-escalation of care. ${ }^{4}$ PFMs may therefore be a useful aid (together with other clinical assessments) in the estimation of the severity of bronchospasm and airway obstruction.

For the above reasons, current clinical practice guidelines advocate the measurement of PEFRs in the management of bronchospasm. ${ }^{5,6}$ Despite this recommendation, our anecdotal observations prior to this study were that PFMs are not routinely used by prehospital emergency care providers in local prehospital emergency care settings. Further to this, we could not find published literature describing the use of PFMs by local prehospital emergency care providers. This prompted us to formally explore and describe a sample of prehospital emergency care providers' knowledge and use of PFMs in Johannesburg, South Africa.

\section{DESIGN AND METHODS}

A prospective quantitative, descriptive design was selected for the study. Data were gathered through the use of a purposefully designed, pre-piloted questionnaire with mostly closed questions. The questions focused on exploring aspects relating to respondents' knowledge and use of the PFM, including their access to the device for patient care. All respondents were operational staff working for a public sector emergency medical service (EMS) in Gauteng province. Data were gathered during August and September 2018. Responses from completed questionnaires were analysed descriptively for each question with the percentage of "yes", "no", correct or incorrect responses being tallied. Ethical clearance for the study was obtained from the University of Johannesburg's Faculty of Health Sciences Research Ethics Committee.

\section{RESULTS}

\section{Demographics}

The final sample consisted of 50 respondents. Of those, 22/50 (44\%) held basic life support (BLS) qualifications, 16/50 (32\%) were intermediate life support (ILS) qualified, and the remaining 12/50 (24\%) were qualified as advanced life support (ALS) providers. Regarding their experience in the EMS, $15 / 50(30 \%)$ of the respondents indicated having between one and five years of experience. A further 16/50 (32\%) had six to ten years of experience, with $19 / 50$ (38\%) having more than ten years' experience.

Responses to the questions are summarised in Table 1, and are presented according to respondents' practice category (BLS, ILS or ALS).

\section{DISCUSSION}

PFMs measure the speed of airflow from the lungs during a forced exhalation. There is evidence that recording and monitoring PEFRs may be useful in the diagnosis and management of acute asthma. ${ }^{6}$ Consequently, both local and international clinical practice guidelines advocate the use of PFMs in the management of asthmatic cases. ${ }^{5,6}$ However, the data summarised in Table 1 shows that participants had insufficient knowledge and understanding regarding the value and use of these devices.

The respondents' levels of knowledge and understanding noted in our study were closely linked to the registered level of care. This level of care (BLS, ILS or ALS) one may provide is, in turn, a function of the level and extent of training one receives. BLS providers demonstrated the lowest levels of knowledge regarding the value and use of PFMs in prehospital care, with only 9\% stating they received any formal training on how to use the device. Such findings may, in part, be due to the known limitations of the now phased out BLS short courses. Many of these basic ambulance courses were only a few weeks in duration, yet historically, up until 2018, the completion of such allowed for registration with the Health Professions Council of South African (HPCSA). ${ }^{7}$ 
It was also interesting to note that, even though $24 \%$ of the respondents said they had been trained to use a PFM, only $8 \%$ indicated they had ever used the device on a patient. This finding appears to be linked to responses that illustrated the device is not readily available in ambulances. The absence of the device in local EMS vehicles is concerning if the PEFRs measurement for asthma cases is deemed to be best practice, and since literature shows EMS providers are commonly dispatched to asthmatic cases. ${ }^{1,8}$

Table 1: Question Responses

\begin{tabular}{|c|c|c|c|c|}
\hline Question & BLS & ILS & ALS & Group \\
\hline $\begin{array}{l}\text { Have you been trained to use a } \\
\text { peak flow meter? }\end{array}$ & $0 / 22$ & $3 / 16(19 \%)$ & $9 / 12(75 \%)$ & $12 / 50(24 \%)$ \\
\hline $\begin{array}{l}\text { How were you trained to use the } \\
\text { peak flow meter? }\end{array}$ & - & OSCE/Sim & $\begin{array}{l}\text { Theory/OSCE/ } \\
\text { Sim }\end{array}$ & - \\
\hline $\begin{array}{l}\text { Have you personally used a peak } \\
\text { flow meter on a patient before? }\end{array}$ & $0 / 22$ & $1 / 16(6 \%)$ & $3 / 12(25 \%)$ & $4 / 50(8 \%)$ \\
\hline $\begin{array}{l}\text { Do you have a peak flow meter in } \\
\text { your ambulance/response vehicle? }\end{array}$ & $0 / 22$ & $0 / 16$ & $0 / 12$ & $0 / 50$ \\
\hline $\begin{array}{l}\text { What is a peak flow meter used to } \\
\text { measure?* }\end{array}$ & $7 / 22(32 \%)$ & $2 / 16(13 \%)$ & $9 / 12(75 \%)$ & $18 / 50(36 \%)$ \\
\hline $\begin{array}{l}\text { What is the unit measurement of } \\
\text { peak expiratory flow?* }\end{array}$ & $2 / 22(9 \%)$ & $7 / 16(32 \%)$ & $10 / 12(83 \%)$ & $19 / 50(36 \%)$ \\
\hline $\begin{array}{l}\text { What zone is indicative of a medical } \\
\text { emergency?* }\end{array}$ & $16 / 22(73 \%)$ & $13 / 16(81 \%)$ & $9 / 12(75 \%)$ & $38 / 50(76 \%)$ \\
\hline
\end{tabular}

*Indicates the percentage of correct responses; OSCE = objective structured clinical examination; Sim = simulation; BLS = basic life support; ILS = intermediate life support; ALS = advanced life support

At face value, the above findings point to a need for 'refresher' training for EMS personnel in the use of the PFMs as part of their management of asthmatic cases. Local EMS also need to explore ways of procuring PFMs (which are not hugely expensive devices) and making them available for use in their vehicles.

Additional comparisons between the above findings to existing literature remain limited due to the absence of prior studies describing the use of PFMs by local prehospital emergency care providers. Further research is therefore recommended with greater sample sizes, including participants from public and private service providers.

\section{LIMITATIONS}

As with all research, we acknowledge the following potential limitations in this study. A sample size of 50 may be considered small, and all our respondents were from a single public sector EMS provider. We categorised respondents according to the level of care provided and did not explore their qualifications in depth nor the year in which these were obtained. While we believe our findings remain interesting and relevant, there is a need for further research on the availability and use of PFMs by emergency care providers in local pre-hospital contexts.

\section{CONCLUSION}

PFMs are useful in measuring the speed of airflow from the lungs during a forced exhalation. Clinical practice guidelines advocate the use of PFMs in the management of acute asthma. ${ }^{6}$ Even though EMS crews are commonly dispatched to asthmatic patients, the respondents in this study demonstrated a general lack of knowledge and understanding of PFMs. PFMs do not appear to be readily available on ambulances, and consequently, few respondents indicated they had ever used a PFM on a real patient. Additional training for EMS crews on the value and use of PFMs in caring for asthmatic patients is recommended, along with the procurement and availability of these devices in local ambulances. There is also a need for more research in this area with greater sample sizes, including participants from both public and private service providers.

\section{CONFLICTS OF INTEREST}

The authors report no conflicts of interest. 


\section{AUTHOR CONTRIBUTIONS}

CVL and CN conceptualised the research. CVL supervised the research and drafted the manuscript. $\mathrm{CN}$ gathered and analysed the data, critically revised and approved the manuscript.

\section{REFERENCES}

1. Lalloo UG, Ainslie GM, Abdool-Gaffar MS, et al. Guideline for the management of acute asthma in adults: 2013 update. S Afr Med J. 2012;103:189-98.

2. Beharry S, Gidla D, Maharaj A, et al. Reality and understanding of asthma control. Chron Respir Dis. 2015;12:340-6.

3. van der Wiel E, Postma DS, van der Molen T, Schiphof-Godart L, Ten Hacken NH, van den Berge M. Effects of small airway dysfunction on the clinical expression of asthma: A fo- cus on asthma symptoms and bronchial hyperresponsiveness. Allergy 2014;69:1681-8.

4. Dakin J, Mottershaw M, Kourteli E. Lung function tests: a hands-on guide. Boca Raton: CRC Press, 2017.

5. Cross D, Nelson HS. The role of the peak flow meter in the diagnosis and management of asthma. J Allergy Clin Immunol. 1991;87:1208.

6. British Thoracic Society Scottish Intercollegiate Guidelines Network. British guideline on the management of asthma. Thorax 2008;63:1-121.

7. Lightner L, Brywczynski J, McKinney J, Slovis CM. Shortness of breath prehospital treatment of respiratory distress. JEMS 2010;35:56-63.

8. Snooks H, Halter M, Palmer Y, Booth H, Moore F. Hearing half the message? A re-audit of the care of patients with acute asthma by emergency ambulance crews in London. Qual Saf Health Care 2005;14:455-8. 